\title{
Eclesiología conciliar latinoamericana y discurso historiográfico: un estudio crítico de La Iglesia en el Perú de Jeffrey Klaiber S. J.
}

\section{Latin American conciliar ecclesiology and bistoriographic discourse: a critical study of The Church in Peru by Jeffrey Klaiber S. J.}

Juan Miguel Espinoza Portocarrero ${ }^{1} \mathrm{y}$

Rolando Iberico Ruiz ${ }^{2}$

Departamento de Teología-PUCP

\section{Resumen}

El libro La Iglesia en el Perú de Jeffrey Klaiber S. J. es una obra de consulta necesaria para el estudio de la historia de la Iglesia católica en el Perú republicano. Como homenaje a Jeffrey Klaiber, los autores analizan las bases eclesiológicas de la narrativa histórica de este libro y resaltan la influencia del proceso de recepción del Concilio Vaticano II (1962-1965) mediado por las Conferencias Generales del Episcopado Latinoamericano de Medellín (1968) y Puebla (1979). El artículo aplica este análisis a la división temporal de la obra de Klaiber, que distingue entre el siglo XIX, la primera mitad

1 Estudiante del Master of Divinity en la Escuela de Teología y Ministerio de Boston College y docente auxiliar del Departamento de Teología de la Pontificia Universidad Católica del Perú. Código ORCID: 0000-00019813-9833. Contacto: jmespinozap@pucp.pe

2 Estudiante de posgrado en la Facultad de Teología de la Universidad Católica de Lovaina y docente auxiliar del Departamento de Teología de la Pontificia Universidad Católica del Perú. Código Orcid: 0000-00032967-4036. Contacto: ribericor@pucp.pe 
del siglo XX y la recepción conciliar entre 1955 y 1985. Se relevan los aportes de la obra de Klaiber, las limitaciones y las perspectivas que abrió para la investigación posterior sobre el catolicismo peruano.

Palabras clave: Jeffrey Klaiber S.J., recepción del Concilio Vaticano II, Concilio Vaticano II, eclesiología latinoamericana, Iglesia católica en el Perú, siglo XIX, siglo XX

\section{Abstract}

The book La Iglesia en el Perú written by Jeffrey Klaiber S.J. is a classic of necessary consultation for the study of Catholicism in the $19^{\text {th }}$ and $20^{\text {th }}$ centuries in Peru. As a tribute to Jeffrey Klaiber, the authors analyze the ecclesiological bases of the historical narrative of La Iglesia en el Perú. The article highlights how Klaiber's work is shaped by the process of reception of the Second Vatican Council (1962-1965) mediated by the General Conferences of the Latin American Episcopate gathered in Medellín (1968) and Puebla (1979). Besides, it examines the temporal division of La Iglesia en el Perú, which distinguishes between the $19^{\text {th }}$ century, the first half of the $20^{\text {th }}$ century, and the conciliar reception from 1955 to 1985 . The text draws on Klaiber's contributions, limitations, and the perspectives it opened for subsequent scholar research on Peruvian Catholicism.

224 Keywords: Jeffrey Klaiber S.J., reception of the Second Vatican Council, Second Vatican Council, Latin American ecclesiology, Catholic church in Peru, $19^{\text {th }}$ century, $20^{\text {th }}$ century 


\section{Introducción}

La lectura de La Iglesia en el Perú de Jeffrey Klaiber S. J., publicada en 1988 y reeditada en 1996, es indispensable para quien le interesa comprender el devenir de la Iglesia católica en el Perú en el periodo posterior a la Independencia y, especialmente, en el escenario abierto por el Concilio Vaticano $\mathrm{II}^{3}$. Si bien la prolífica producción intelectual de Klaiber puede hallarse en diversos libros y revistas académicas, el trabajo referido condensa el marco interpretativo que este autor construyó para conceptualizar la presencia de la Iglesia católica en la sociedad peruana y que, de una u otra forma, moldea sus textos posteriores. A semejanza de lo que Jorge Basadre representa para la historia del Perú republicano, la periodización y las categorías que Klaiber expone en La Iglesia en el Perú constituyen una referencia obligada sobre la que se anclan investigaciones posteriores sobre el catolicismo peruano.

Por tales motivos, el estudio crítico de este trabajo y el rescate de sus aportes a la historiografía sobre el catolicismo peruano es un acto de justicia. Son muchas las aproximaciones desde las cuales es posible analizar esta obra. El estilo de hacer historia de Klaiber no se restringió a la tradicional historia institucional de la Iglesia, sino que incorporó los enfoques de la historia social y cultural, la historia intelectual y la historia política. En este artículo, nos enfocamos en develar los supuestos teológicos que influenciaron el análisis de este autor. La experiencia de ser un jesuita formado durante los años del Concilio Vaticano II y un protagonista de la recepción de este evento en Latinoamérica marcaron decisivamente el tipo de preguntas que se planteó y su comprensión del proceso

3 La Iglesia en el Perú tiene tres ediciones, la primera de marzo de 1988, la segunda de agosto de 1988 y la última de mayo de 1996. En realidad, no hay modificaciones sustanciales entre ellas. Por lo tanto, en este ensayo, citamos indistintamente la segunda y la tercera edición. 
histórico de la Iglesia peruana. En otras palabras, en la obra magna de Klaiber subyace una noción de Iglesia que corresponde no solo a un marco teórico, sino a su praxis en el seno de la institucionalidad católica y a su posición respecto a los debates internos abiertos por el Concilio Vaticano II.

Dicho esto, presentamos nuestra hipótesis para luego explorarla en los dos grandes periodos de la historia del catolicismo en el mundo posterior a la Revolución francesa: 1) la implantación y la hegemonía del proyecto del ultramontanismo del siglo XIX y la primera mitad del XX y 2) el Concilio Vaticano II y sus ecos en el catolicismo de la segunda mitad del siglo XX.

\section{Nuestro planteamiento}

Es conocido que el Concilio Vaticano II, celebrado entre 1962 y 1965, constituye un evento paradigmático en la historia de la Iglesia, como afirma el teólogo e historiador italiano Massimo Faggioli (2012), tanto por lo que allí pasó como por lo que pasó después y los debates que se abrieron respecto a su interpretación. La recepción de las reformas conciliares fue y sigue siendo ocasión de importantes innovaciones teológicas, eclesiológicas y pastorales, y también es motivo de polémicas intraeclesiales y extraeclesiales sobre la auténtica interpretación del Concilio y la legitimidad de algunas de sus formas de recepción "no previstas".

En este sentido, la construcción de narrativas históricas se ha empleado para legitimar posiciones de redes de actores eclesiales y sus posiciones teológicas y políticas. Ejemplo de ello son las "guerras político-intelectuales" en el seno del catolicismo posconciliar sobre asuntos controversiales como la resistencia al Vaticano II (Menozzi, 1987) o la teología de la liberación en Latinoamérica (Congregación para la Doctrina 
de la Fe, 1984 y 1986; Menéndez 2002; Pásara, 1986; Peña, 1995), las polémicas sobre la encíclica Humanae vitae de Pablo VI y la teología moral luego de la revolución sexual (Massa, 2018). Particularmente, hoy son visibles en la reforma de la Iglesia planteada por el papa Francisco a partir de una interpretación del Concilio Vaticano II que alienta el modelo de la sinodalidad (Comisión Teológica Internacional, 2018). Altamente resistida, la reforma del papa Francisco apuesta por consolidar la participación de todos los miembros de la comunidad eclesial en la misión de la Iglesia y, por tanto, la descentralización y la desclericalización del gobierno y la praxis eclesiástica (Galli, 2016; Ivereigh, 2019; Luciani, 2016).

Al respecto, Faggioli asevera que es imprescindible la historización del Vaticano II y de sus procesos de recepción para que los usos del pasado abandonen la lógica proselitista y legitimista (2012, p. 139-144). Más bien, este autor aboga por interpretaciones del evento conciliar que se inscriban en una hermenéutica que, respetando el espíritu del acontecimiento, afiancen nuestra comprensión del mismo. De esta manera, la Iglesia será capaz de responder a los desafíos del presente de acuerdo con lo que el teólogo alemán Peter Hünermann (2014) denomina el "marco constitucional de la fe", que orienta a la Iglesia en el siglo XXI. En este sentido, la historia de la Iglesia se proyecta como memoria y acto eclesial que inspira el camino de la comunidad cristiana. A nuestro juicio, la obra historiográfica de Jeffrey Klaiber se inserta en esta dinámica de configurar la historia de la Iglesia en una perspectiva teológica que promueve el cambio eclesial a la luz del concilio.

Nuestra lectura es que la interpretación histórica sobre la Iglesia peruana que construye Klaiber no solo está constituida sobre los procesos iniciados por el Vaticano II y su particular recepción en América Latina. Su interpretación es un instrumento de legitimación de la eclesiología posconciliar, 
es decir, de la manera como se comprende la naturaleza y la misión de la Iglesia en el mundo contemporáneo en los documentos conciliares y en los ensayos pastorales surgidos en Latinoamérica a partir de la 2. ${ }^{a}$ Conferencia General del Episcopado Latinoamericano en Medellín (CELAM, 1968). Esto se ve claro en la obra de Klaiber cuando hace la historia del posicionamiento de la Iglesia peruana ante los cambios de la modernización cultural de mediados del siglo XX y de los procesos de la política nacional durante la etapa republicana. Además, incorpora en su análisis las controversias intracatólicas sobre el significado del Concilio -particularmente aquella sobre la teología de la liberación-, lo que genera interpretaciones que constituyen una toma de posición y una valoración crítica de dichos procesos para la praxis de la Iglesia peruana y latinoamericana.

\section{Historiografía y eclesiología: una mirada sobre una relación compleja}

A fin de resaltar las bases teológicas de la producción histórica de Klaiber, es clave detenernos a reflexionar sobre la relación entre historiografía y teología. Eusebio de Cesarea, autor de la primera historia eclesiástica, inauguró este género como un ejercicio intelectual que intenta darle identidad a la comunidad de fieles y mediar la relación de la institución eclesiástica con las estructuras políticas y el universo cultural de un contexto histórico determinado ${ }^{4}$. Por lo mismo, en la interpretación histórica se filtran preconceptos teológicos. Por ello, el historiador jesuita John O’Malley promueve una mayor integración de la historia de la Iglesia con la teología sistemática y, particularmente, con la eclesiología, que es la

4 Para un estudio crítico del proyecto intelectual de Eusebio de Cesarea durante el reinado del emperador Constantino, véanse Drake (1976) y Chestnut (1986). 
disciplina teológica que trata el misterio de la Iglesia (1982, p. 190). En el quehacer del historiador eclesiástico existe una noción subyacente sobre qué es la Iglesia y cómo realiza su misión, sobre quiénes la componen, y quiénes son sus interlocutores fuera de ella. Estos conceptos de eclesiología constituyen ejes del marco de análisis que determinan la selección y el trabajo de la información, así como la construcción de la narrativa histórica.

Es decir, el discurso historiográfico sobre la Iglesia se fundamenta en la eclesiología o la teología de la Iglesia, que requiere hacerse explícita para comprender la posición con la que se escribe y los límites de la interpretación. De igual manera, como la eclesiología se inserta en una tradición historiográfica, es necesario analizar los préstamos conceptuales y su empleo en el desarrollo de la narrativa historiográfica. Por ello, la relación entre el discurso historiográfico y la teología es crucial para entender los marcos de referencias de los historiadores de la Iglesia, sus intereses, sus aportes y sus limitaciones. Esta relación vale para la historiografía que podríamos denominar "católica" o "comprometida", que suele ser la impartida en las facultades eclesiásticas con el nombre de "historia de la Iglesia", así como para la "secular" que se aproxima con una mirada externa a la institución y la tradición religiosa. Así, se puede afirmar que la eclesiología influye en la construcción de categorías historiográficas para estudiar y comprender la Iglesia y su relación con el entorno (Iberico, 2015).

Un ejemplo interesante del cruce entre la historiografía y la eclesiología es la obra del historiador jesuita Rubén Vargas Ugarte. En el quinto tomo de su Historia de la Iglesia en el Perú, 1800-1900, al abordar la revolución de 1854 y la Convención Nacional de 1856, Vargas Ugarte califica a los liberales como católicos de nombre porque "tenían una idea completamente falsa de sus deberes como tales y no sa- 
bían reconocer los derechos de la Sociedad perfecta fundada por Jesucristo y de la cual se confesaban súbditos" (1962, p. 227). Sin entrar a discutir la pluralidad de actores eclesiales y políticos del Perú a mitad del siglo XIX, Vargas Ugarte era heredero de un esquema historiográfico-teológico asociado al ultramontanismo decimonónico. La obra del historiador jesuita está impregnada de la noción eclesiológica de "sociedad perfecta" que señala la inmutabilidad institucional y doctrinal de la Iglesia católica a lo largo de los siglos (Granfield, 1979; Wood, 2011, pp. 3-4). La interpretación histórica de Vargas Ugarte se comprende solo dentro de la teología ultramontana consolidada durante el siglo XIX en el catolicismo global y peruano, y que además elaboró un mapa completo de los enemigos de la Iglesia clasificados en categorías como "regalistas", "injerencia", liberales, masones, socialistas, etc.

La historia de la Iglesia del padre Jeffrey Klaiber no está exenta de esta relación con la eclesiología. La reflexión teológica contemporánea en América Latina emergió del cruce de circunstancias históricas marcadas por la injusticia social, la violencia y la pobreza, con una Iglesia institucionalmente sólida y una presencia pública reconocida. Esta transformación teológica coincidió con el progresivo proceso de cambio interno de la Iglesia. La teología latinoamericana recogió las intuiciones conciliares para elaborar una reflexión sobre el papel de la Iglesia en una sociedad en transformación socio-política y cultural. El tiempo de recepción conciliar en América Latina se caracterizó por una lectura centrada en el compromiso de la Iglesia católica con la justicia social y los sectores excluidos. Este discurso moldeó la actividad pastoral, la reflexión teológica y el compromiso político de varias generaciones de creyentes. En este escenario, Jeffrey Klaiber escribió su obra más emblemática, La Iglesia en el Perú: Su historia social desde la independencia y la dedicó al "Pequeño Reino de San Cayetano", aquel barrio del distrito popular limeño de El Agustino donde realizó su trabajo pastoral. 
El Concilio Vaticano II (1962-1965) abrió un nuevo ambiente teológico en toda la Iglesia católica que permitió la emergencia de una diversidad interna y el surgimiento de corrientes de pensamiento como la teología de la liberación. En la Constitución dogmática Lumen gentium, el concilio retomó el paradigma bíblico para afirmar que la Iglesia constituye un "nuevo pueblo de Dios" que peregrina en este mundo y en esta historia (LG 9). De esta manera, el Vaticano II reformulaba la comprensión de la Iglesia como una societas perfecta, propia de la eclesiología ultramontana y romana decimonónica, y como un cuerpo místico rígidamente "orgánico y jerárquico", según Pío XII en la encíclica Mystici corporis Christi de 19435. En este "nuevo pueblo de Dios", la primacía la tiene el sacramento del bautismo por el cual todos los fieles son incorporados a la Iglesia, y sin el cual no existe la posibilidad de participar en los otros sacramentos. Esta afirmación es especialmente válida para los miembros ordenados sacramentalmente. De esta manera, la Lumen gentium puso en el mismo plano de igualdad sacramental, por lo menos a nivel teológico y eclesiológico, a los fieles y ministros ordenados.

En esta misma línea se encuentra la Constitución pastoral sobre la Iglesia en el mundo actual Gaudium et spes. El documento destila una actitud positiva sobre la interacción

5 El concepto de "cuerpo místico", en su definición decimonónica, justificó una eclesiología relacionada con el concepto de Iglesia como societas perfecta superior a la sociedad imperfecta, que es el Estado (Granfield, 1979). Por su parte, en el siglo XX, este mismo paradigma eclesiológico resaltó la unidad orgánica, sacramental y jerárquica entre los miembros de la Iglesia (Parra, 2009, pp. 807-811). Fue incorporado en la Constitución Dogmática Lumen gentium junto al también término bíblico "pueblo de Dios". En la recepción inmediata del Vaticano II, el concepto "pueblo de Dios" fue crucial para articular una relectura de la Iglesia basada en las realidades concretas de los fieles. 
entre la Iglesia, "el pueblo de Dios", y la "familia humana", con la cual comparte "los gozos y las esperanzas, las tristezas y las angustias" (GS, 1). Gaudium et spes pone en el centro la historicidad de la Iglesia en su relación con el mundo, pues ella misma se encuentra peregrinando en la historia humana. De esta manera, el "pueblo de Dios" no constituye una abstracción sacramental, sino una comunidad sumergida en el devenir socio-político, económico y cultural de la humanidad.

Gaudium et spes y Lumen gentium fueron documentos claves en la recepción que los obispos latinoamericanos hicieron del Concilio en su 2. ${ }^{a}$ conferencia general en Medellín. El título del documento conclusivo, La Iglesia en la actual transformación de América Latina a la luz del Concilio (CELAM, 1968), revela de entrada cómo los cambios en la historia del continente resultaban fundamentales para ubicar al "pueblo de Dios" como actor colectivo de dicho proceso histórico. Más aún, la transformación histórica de las condiciones concretas del continente es deseada por el "pueblo de Dios en América Latina"6. Por tanto, la acción de la Iglesia ad extra, es decir, presente en el mundo para luchar contra las injusticias, se convirtió en el sello de identidad de un sector prominente e intelectualmente activo de la Iglesia latinoamericana.

Desde esta perspectiva eclesiológica, Jeffrey Klaiber interpretó la historia de la Iglesia católica peruana, en el contexto latinoamericano, como una lucha por la liberación de estruc-

6 En las conclusiones, el documento titulado Paz afirma que "el pueblo de Dios en América Latina, siguiendo el ejemplo de Cristo, deberá hacer frente con audacia y valentía al egoísmo, a la injusticia personal y colectiva" (cf. Paz, 14). Igualmente, con relación al tema de la violencia, los obispos afirman: "nos dirigimos, como pastores, a todos los miembros del pueblo cristiano para que asuman su grave responsabilidad en la promoción de la paz en América Latina” (cf. Paz, 16). 
turas sociales y políticas injustas, así como un proceso de autoliberación de los oprimidos de dichas estructuras anquilosantes y alienantes. En la visión intelectual de Klaiber influyó el esfuerzo de la Comisión para el Estudio de la Historia de las Iglesias en América y el Caribe (CEHILA) y la preparación, con la coordinación del filósofo Enrique Dussel, de la Historia general de la Iglesia en América Latina, publicada en 10 volúmenes entre 1983 y 1994. En esta empresa, Jeffrey Klaiber (1987a) participó encargándose del volumen VIII dedicado a la región andina (Colombia, Ecuador, Perú y Bolivia). La clave hermenéutica de la CEHILA estaba en desentrañar en la historia eclesial los desencuentros entre la Iglesia popular, el "pueblo de Dios latinoamericano" y la Iglesia oficial, jerárquica y ajena al devenir histórico (Dussel, 1983). En ese discurso, la Iglesia oficial latinoamericana estuvo caracterizada por mirar solamente a Roma y sus exigencias jurídico-doctrinales. Esta relación de dependencia con el centro romano tan solo se transformaría - no sin resistenciascon el impacto del Vaticano II y su recepción continental. La emergencia de una identidad latinoamericana propia y madura, en esta lectura, solo fue posible y se produjo en el periodo posconciliar.

La Iglesia en el Perú se publicó un año después de la aparición del volumen de la CEHILA dedicado al catolicismo en la región andina. Como veremos, el análisis de Klaiber está influenciado por las claves hermenéuticas de la CEHILA. Sin embargo, este autor introduce matices importantes respecto a la narrativa de la CEHILA, debido a su propia lectura del contexto de recepción de la 3. ${ }^{a}$ Conferencia General del Episcopado Latinoamericano reunido en Puebla en 1979 y de los debates político-teológicos alrededor de la legitimidad de la reflexión teológica y la práctica pastoral de la teología de la liberación. A continuación, examinaremos detenidamente los argumentos principales del libro de Klaiber siguiendo su periodización y las preguntas analíticas planteadas. 


\section{El largo siglo XIX del catolicismo peruano ${ }^{7}$}

La Iglesia en el Perú comienza con una visión panorámica de los siglos XIX y XX en la que su autor analiza la Iglesia en su doble dimensión: ad intra y ad extra. El análisis de las permanencias y cambios institucionales se enmarcan en el desenvolvimiento eclesial del contexto peruano. Haciendo eco de la eclesiología de Gaudium et spes, Klaiber afirma que "la Iglesia en el Perú, [...], ha sido influida, moldeada y condicionada por el medio social en el que existe" $(1988$, p. 18). Desde su inicio, esta obra recoge las claves hermenéuticas conciliares para comprender la historia del catolicismo peruano. En el primer capítulo de balance, menciona que la Iglesia colonial padecía de "falta de conciencia eclesial", dado su lugar privilegiado en la vida social y política de entonces (p. 27). Esta condición produjo una falta de espíritu combativo y de conciencia de pertenencia eclesial entre sus miembros. La Iglesia era parte del aparato político y social, y no constituía una comunidad animada capaz de dinamizar procesos históricos en el país. Para Klaiber, la superación de ambas condiciones eclesiales se inició a partir de la segunda mitad del siglo XIX y culminó con la maduración de la identidad eclesial peruana tras el Concilio y su recepción en Medellín.

Jeffrey Klaiber analiza la historia de la Iglesia preconciliar, este "largo siglo XIX", con varias categorías teológicas prove234 nientes del Vaticano II y las categorías propias de la teología latinoamericana. En su balance se entrecruzan temas, como

7 La expresión ha sido tomada del capítulo 2 "The Long Nineteenth Century" del libro de John O'Malley, What Happened at Vatican II (2010). El capítulo enfatiza la larga permanencia de los rituales, el rechazo a la modernidad política y la teología ultramontana como temas centrales para la Iglesia en el contexto posterior de la Revolución francesa. Estos fueron algunos de los aspectos resignificados por el Concilio Vaticano II. 
la relación entre la fe y la ética pública, el clericalismo, el fraccionamiento social de la Iglesia como reflejo de la jerarquización social peruana, y la ruptura entre Iglesia oficial y la religiosidad popular. El peso del "legado colonial" que, de acuerdo con el autor, ha "afectado a la Iglesia latinoamericana en su desarrollo" es crucial para entender el retraso del surgimiento de una identidad en la Iglesia peruana y latinoamericana. En sus palabras, la "Iglesia de la época republicana estuvo profundamente marcada por la experiencia colonial" (p. 35) que solo se rompió con Medellín, que "significó el nacimiento de una Iglesia latinoamericana con un sentido de su propia identidad y con una penetrante comprensión del medio social en que se encontraba" (p. 380). Por tanto, su proyecto historiográfico recorre ese proceso teológico y eclesiológico de la Iglesia en el Perú.

Para el siglo XIX, Klaiber destaca cinco aspectos que permiten entender ese primer proceso histórico del catolicismo. El primero es que la Iglesia tuvo "una vida institucional débil" que movió al conjunto de la jerarquía hacia Roma en busca de "un contrapeso a la dependencia del Estado" (p. 30). De esta manera, durante el siglo XIX, el "papado vino a ser la 'espina dorsal' que faltaba a la Iglesia colonial" (p. 30). No obstante, este proceso denominado como la "romanización" de la Iglesia peruana consolidó una "Iglesia oficial" formada por obispos, sacerdotes y religiosos, aunque no mandaban necesariamente sobre la totalidad de la Iglesia. De hecho, la práctica religiosa en el Perú se caracterizó por "pequeños núcleos de fieles practicantes y, más allá de ellos, una masa de cristianos vagamente identificados con el catolicismo mediante ciertos signos exteriores y ciertas prácticas piadosas" (p. 30).

El segundo aspecto constituye el fraccionamiento socio-cultural de la Iglesia. A pesar de que la Iglesia "abarca a todas las razas, todas las clases sociales y todos los estratos culturales", 
ella fue un mini modelo de la sociedad (p. 31). Para el autor, esta correlación de la Iglesia con la sociedad peruana se reflejó en la división intraeclesial entre la ciudad y el campo: la Iglesia "oficial" instaurada en las urbes vinculaba a las clases altas y medias, mientras los campesinos estaban "al margen de esta Iglesia más 'oficial' (p. 31). De esta manera, la debilidad institucional y las condiciones históricas del país se reflejaron en la falta de comunión e institucionalidad en el conjunto del "pueblo de Dios" en el Perú.

Un tercer elemento es la relación 'patrón-cliente' entre el presbítero y el laicado. Esta relación emanaba del entendimiento del sacerdocio como una carrera más que como una vocación. Sin hacer una referencia explícita, Klaiber reconoce el carácter clerical de esta herencia eclesial colonial y republicana que promovía una mayor división entre estas Iglesias (p. 32). El cuarto elemento ha sido el "divorcio entre la Iglesia y la religión" que se muestra en la vida eclesial peruana a través de la oposición entre la Iglesia oficial o institucional y la vivencia de la religiosidad popular (Klaiber 1988, p. 33). Si bien Klaiber no asume con radicalidad las categorías de Iglesia oficial e Iglesia popular, como lo hicieron algunas propuestas historiográficas y eclesiológicas vinculadas a la teología de liberación (Boff, 1984; Dussel 1979 y 1983; Richard, $1980)^{8}$, sí las incorpora parcialmente para comprender a la Iglesia republicana. Este dualismo eclesial, matizado por Klaiber en el entrecomillado de Iglesia "oficial" y la omisión del término "Iglesia popular", remite a una visión teológi-

8 Leonardo Boff afirma sobre la Iglesia que "existe, en cambio, una tensión y acaso una oposición entre un tipo de iglesia que a veces prolonga su encarnación dentro de una cultura dominantemente burguesa, con sus respectivos intereses, y este nuevo tipo de iglesia, que se encarna en la cultura popular, se modifica, asume la causa del pueblo y, por ello mismo, se llama justamente iglesia popular" (1984, p. 454). Sobre los debates eclesiológicos originados por la teología de la liberación, véase Gibellini, 1998, pp. 398-400. 
ca de la historia eclesial en el Perú y Latinoamérica desde la perspectiva de la teología de la liberación. Esta oposición de origen colonial ha caracterizado la historia de la Iglesia republicana o, en palabras de Klaiber, "la Iglesia republicana estuvo profundamente marcada por la experiencia colonial" (1988, p. 35).

Finalmente, Klaiber resalta como quinto elemento el "divorcio entre ética y religión o entre normas públicas y práctica real", que constituye una mirada a la historia de la Iglesia en el Perú con las claves del Concilio Vaticano II. La Gaudium et spes se refiere a este tema de la siguiente manera:

El Concilio exhorta a los cristianos, ciudadanos de la ciudad temporal y de la ciudad eterna, a cumplir con fidelidad sus deberes temporales, guiados siempre por el espíritu evangélico. Se equivocan los cristianos que, pretextando que no tenemos aquí ciudad permanente, pues buscamos la futura, consideran que pueden descuidar las tareas temporales, sin darse cuenta que la propia fe es un motivo que les obliga al más perfecto cumplimiento de todas ellas según la vocación personal de cada uno. [...] El divorcio entre la fe y la vida diaria de muchos debe ser considerado como uno de los más graves errores de nuestra época. (GS, 43)

Por tanto, la separación entre ética y religión es uno de los desafíos propios de la herencia colonial y republicana de la Iglesia al que se le presta atención en el nuevo modelo eclesial surgido del Concilio y su recepción desde Medellín. En palabras de Klaiber, "el resurgimiento del 'sentido de Iglesia' en las comunidades cristianas actuales también va acompañado por una nueva sensibilidad hacia la moral personal y social" (1988, p. 34).

De los aspectos característicos del devenir eclesial, Klaiber plantea una clasificación temporal para comprender la historia de la Iglesia peruana a partir de su interacción con la 
sociedad. Para la etapa que va hasta los años inmediatos al Vaticano II, el autor plantea tres "etapas de evolución": 1) Crisis y restauración (1821-1855), 2) La Iglesia militante (1855-1930), y 3) El laicado militante (1930-1955). Para la primera etapa, Klaiber recoge los matices propios de la época como la presencia del regalismo doctrinario entre los primeros liberales, así como la progresiva transformación de la Iglesia durante ese periodo. En ese tiempo, "el ataque liberal fue relativamente suave" y la "Iglesia fue plenamente restaurada: más conservadora, pero intacta” (pp. 35-36).

En el segundo momento, de la "Iglesia militante", los cambios ideológicos iniciados por el liberalismo, cada vez más anticlerical, y del positivismo y el anarquismo de finales del siglo XIX, promovieron una postura "militante" entre los católicos. El ascenso del papado como soporte simbólico de la "causa católica frente al liberalismo" se acompañó de la fundación de sociedades y partidos políticos (pp. 38-39). Una mentalidad católico-conservadora se instaló en las clases altas y medias, junto a la mentalidad "liberal-positivista". Sin embargo, para Klaiber, el periodo reveló la falta de "una honda conciencia de identificación con la Iglesia [entre los católicos]", por lo que esta se asoció con el poder político y económico (p. 39). Para el historiador jesuita, este momento es clave en la consolidación de una Iglesia "agresiva", con una "pastoral tradicional" e incapaz de atraer a "los hombres con una mentalidad más moderna y más crítica frente al orden establecido" (pp. 40-41).

Finalmente, la tercera etapa consistió en el surgimiento del laico "como defensor de la Iglesia y como portavoz de la causa católica". En ese escenario, nació la Acción Católica en 1935 como un movimiento para la formación laical y el cultivo de un sentido de pertenencia a la misión de la Iglesia. Más concretamente, fue un espacio para que laicos y sacerdotes se "cuestionaran su propia actuación en el mundo a la 
luz del mensaje social de la Iglesia" (pp. 41-43). De alguna forma, esta etapa fue el anticipo al salto modernizador que se introdujo a partir de los ańos cincuenta y que el Concilio Vaticano II aceleró. Sobre estos puntos nos detendremos en la siguiente sección de este artículo.

El esquema "evolutivo" de la historia de la Iglesia peruana de Klaiber otorga una mirada completa de su proceso histórico en el periodo republicano. Se trata de una división temporal que recoge las continuidades coloniales, los cambios progresivos y las nuevas formas del catolicismo. El esquema está definido por los marcos teológicos conciliares enfocados en la interacción de la Iglesia con la sociedad, la política y otros aspectos de la vida del Perú. Dada la influencia de su perspectiva teológica, Klaiber considera que el peso del "legado colonial" y la postura antiliberal del catolicismo decimonónico impidió constituir una Iglesia moderna en términos teológicos y pastorales, es decir, vinculada a las necesidades de la realidad socio-cultural, por lo que no fue capaz de articular a todos sus miembros de manera activa. No obstante, la cronología podría discutirse para complejizar el marco eclesiológico de la obra. Por ejemplo, Klaiber retrasa el protagonismo laical hasta la década de 1930, cuando el papel del laicado se inició tímidamente en 1867 al fundarse la Sociedad Católico-Peruana. Es decir, ya en el siglo XIX, el laicado comenzó a asumir una mayor presencia pública en nombre de la Iglesia, la cual se consolidó progresivamente en el siglo XX. Además, la historia decimonónica de la Iglesia peruana estuvo centrada en los ministros ordenados, fundamentalmente obispos y presbíteros. A pesar de su tangencial crítica al clericalismo, ellos continuaron siendo los grandes actores de la historia eclesial en La Iglesia en el Perú.

El marco eclesiológico de la obra de Klaiber no se agota en las referencias al Concilio Vaticano II y su recepción en América Latina. Algunas de sus categorías para analizar el siglo 
XIX hacen referencia a marcos historiográficos deudores de la teología ultramontana. Como se ha mencionado, Jeffrey Klaiber emplea la eclesiología conciliar, en clara ruptura con su hermano de congregación, Rubén Vargas Ugarte, quien recoge la eclesiología ultramontana de la societas perfecta. Sin embargo, en su narrativa sobre la Iglesia en el Perú decimonónico aparecen categorías y asociaciones acuñadas por los ultramontanos para descalificar a sus detractores, que dan cuenta de su comprensión de la política y la Iglesia. El tratamiento del "liberalismo", el "regalismo" y el "galicanismo" para referirse a los grupos e ideas opuestos a la Iglesia, a la que se asocian conceptos como "antiliberal", "conservador" y "ultramontano", da por supuesto ciertas categorías para analizar el desenvolvimiento histórico del catolicismo en el Perú del XIX. Por ejemplo, al referirse a la política reformista de los Borbones sobre la vida religiosa en las colonias, Klaiber emplea la palabra "injerencia" (p. 64), un término usado en el lenguaje político ultramontano para descalificar las pretensiones reformistas del Estado. La palabra revela el peso del lenguaje teológico ultramontano en la valoración de la relación entre la Iglesia, la sociedad y la política para analizar el siglo XIX. No obstante, Klaiber reconoce que el ascenso del ultramontanismo dentro del catolicismo peruano y global implicó que el "pluralismo que había caracterizado a la Iglesia durante y después de la Independencia, [...] se extinguió en gran parte, y fue suplantado por un unidimensionalismo intelectual frente a la religión, la política y la sociedad" ( $\mathrm{p}$. 70). A pesar de las "trampas sutiles del ultramontanismo", como el empleo del término "injerencia" y de su herencia teológica conciliar y latinoamericana, los matices empleados en La Iglesia en el Perú la convierten en una obra central para entender la historia de la Iglesia peruana durante el largo siglo XIX.

9 La frase ha sido tomada del artículo de Roberto Di Stefano (2015). 


\section{La Iglesia peruana y el Concilio Vaticano II}

El Concilio Vaticano II y su recepción en América Latina en la 2. ${ }^{a}$ Conferencia General del CELAM en Medellín constituye, en la narrativa histórica de la teología de la liberación, un parteaguas para la historia de la Iglesia en el Perú y el continente. En el discurso articulado por los teólogos de la liberación y la comunidad intelectual de la CEHILA, 1968 es el año en que la renovación conciliar cuajó en el continente por medio de una interpretación teológica de la realidad latinoamericana y de la misión de la Iglesia católica ante los retos del subdesarrollo y la dependencia. Las enseńanzas del Vaticano II fueron aterrizadas en el contexto regional por medio de la deliberación de los obispos y teólogos en Medellín. Por ello, en América Latina, la renovación eclesial convocada por el Concilio Vaticano II coincidió y alentó el compromiso con la construcción de una sociedad más democrática y justa (Klaiber, 1996, p. 354). En medio de un clima de difusión de una cultura contestataria a nivel global por el movimiento estudiantil francés de mayo de 1968 y la lucha por los derechos civiles en los Estados Unidos, Medellín se constituyó en un referente cultural local que promovió una "mística" que hacía compatible la fe cristiana con los anhelos de cambiar el mundo.

En líneas generales, Jeffrey Klaiber suscribió esta narrativa histórica. Para él, con el Concilio Vaticano II y, especialmente, su recepción en la conferencia de Medellín, emergió una "nueva Iglesia" más participativa e involucrada con la realidad del país y los sectores marginados. Más aún, para Klaiber, el Perú era uno de los casos emblemáticos de la recepción del Vaticano II y uno de los terrenos más fecundos de la innovación pastoral por la buena disposición de un número importante de obispos. No obstante, en su calidad de historiador, inscribió los ecos de 1968 en un discurso histórico que exploraba los antecedentes y analizaba críticamente sus 
consecuencias. En ese sentido, identificó tres periodos en el desarrollo de la Iglesia peruana del Vaticano II: 1) Modernización y apertura a la cuestión social (1955-1968), 2) la Iglesia durante el régimen de Velasco (1968-1975) y 3) la Iglesia social-pastoral (1975-1985).

Antes de analizar cada uno de los periodos, la interpretación de Klaiber se orienta por la pregunta sobre cómo se transformó la relación entre la Iglesia católica y la sociedad peruana entre 1955 y 1985. En sus palabras, "en conjunto, la Iglesia peruana experimentó una profunda transformación de mentalidad" (Klaiber, 1996, p. 355). Más aún, "en pocos años, bajo el doble impacto del Concilio Vaticano II y la marcha de los acontecimientos en el Perú, la Iglesia pasó de ser observadora de los hechos a ser participante directa en las decisiones y los movimientos populares que estaban transformando la realidad social del país" (p. 352). Este foco del análisis se debe a que, para el autor, el documento clave para entender la recepción del Vaticano II en el Perú y América Latina era la constitución pastoral Gaudium et spes, que imaginaba una vinculación constructiva entre la Iglesia y el mundo contemporáneo (p. 371). Por tanto, su lectura del proceso histórico enfatiza una actitud progresiva en el catolicismo peruano de apertura hacia el mundo secular, tal como lo planteaba Gaudium et spes.

Su argumento central sobre la transformación de la relación entre la Iglesia y la sociedad peruana puede resumirse de la siguiente manera. El punto culmen estaba en el proceso abierto con Medellín, que coincidió con el gobierno militar de Juan Velasco Alvarado, el cual, si bien constituyó un régimen autoritario y dictatorial, sentó condiciones para levantar las reivindicaciones de los sectores populares y confrontar las desigualdades sociales. En distintos niveles, los católicos colaboraron en la implementación de algunas de las reformas del régimen velasquista, aunque simultáneamente se distan- 
ciaron y resistieron otras de ellas. No obstante, Klaiber fue claro en que esta "consciencia social y política" de la Iglesia peruana emergió en los años previos a 1968 entre los círculos del "laicado militante" de la Acción Católica, los misioneros extranjeros y algunos obispos con mentalidad reformadora. Más aún, reconocía las tensiones generadas en el interior de la Iglesia por las opciones asumidas en Medellín y la radicalización de algunos sectores católicos. En su lectura, fue recién en los años ochenta, luego de la 3. ${ }^{a}$ Conferencia General del CELAM en Puebla (1979), cuando se abrió la posibilidad de un equilibrio entre "conservadores" y "progresistas" en torno a lo que denominó un modelo "socio-pastoral", que incorporaba la dimensión social como un aspecto fundamental de la evangelización.

Planteado el argumento central, examinemos cada uno de los capítulos dedicados a la Iglesia peruana en el marco del Vaticano II. El capítulo VIII, "La Iglesia ante los retos de la modernización y la cuestión social (1955-1968)" sitúa los antecedentes al momento abierto por Medellín y las primeras formas de recepción del Vaticano II. Desde la perspectiva de Klaiber, en esos años se produjo la modernización de las estructuras pastorales con la influencia de las doctrinas del desarrollo. Siguiendo el modelo del catolicismo norteamericano, la idea era dar eficiencia a la pastoral, dotando a las estructuras de la Iglesia de rasgos de una "empresa moderna", como la planificación a largo plazo, el manejo racional del personal y el capital, y la coordinación entre los distintos departamentos u oficinas regionales (p. 352). En ese espíritu, se promovió la renovación y reorganización de la burocracia eclesiástica a nivel de las diócesis y de la asamblea de obispos, que pasaron a crear oficinas especializadas para articular los esfuerzos de la educación católica o la asistencia social. Así mismo, se formaron federaciones de las diversas congregaciones religiosas masculinas y femeninas para articular sus esfuerzos en temas comunes. 
Un segundo rasgo de dicho proceso de modernización fue el enganche con la "cuestión social". La Iglesia fue tomando consciencia de su responsabilidad con la sociedad peruana conforme fue expandiendo su presencia en zonas rurales de los Andes y la Amazonía, y en las ciudades donde la migración estaba produciendo un desborde poblacional y una crisis de vivienda. Para Klaiber, la figura del franciscano Juan Landázuri Ricketts, quien asumió como arzobispo de Lima en 1955, ilustraba ese "plan de expansión" con consciencia social. Con el apoyo de la Cáritas Internacional y la agencia norteamericana Catholic Relief Services, implementó la "Misión de Lima", que para Klaiber constituyó "el primer plan de pastoral de conjunto para los barrios marginales" (p. 364).

A nivel nacional, aportó en esta línea el incremento de la presencia del clero extranjero y la implementación de proyectos de desarrollo en zonas de pobreza, tanto urbanas como rurales, que estaban a su cargo. De esa manera, en los años cincuenta se estaba esbozando un modelo pastoral que integraba la evangelización con el desarrollo comunitario de los más pobres. En sus palabras, "al mismo tiempo que la Iglesia se dedicaba a construir nuevos templos, también adoptaba nuevos métodos pastorales, para acercarse a los pobladores de las 'barriadas', que implicaban colaborar a nivel de asistencia humanitaria y la organización de las comunidades locales (p. 364).

De acuerdo con Klaiber, ese momento precursor condujo a la maduración de una "nueva mentalidad social y política" entre los católicos peruanos y los misioneros extranjeros. El contacto con la realidad del "cinturón de pobreza" alrededor de Lima y otras ciudades llevó a varios en la Iglesia a comprender que existía "una crisis estructural que era la verdadera causa del fenómeno de las migraciones masivas desde la Sierra" (p. 364). La preocupación por construir una socie- 
dad justa era compartida por los laicos, como lo demuestra la organización del Partido Demócrata Cristiano (1956) o la Unión Nacional de Empleadores Católicos (1954). No obstante, para Klaiber, los hitos claves fueron la "Carta Pastoral del Episcopado Peruano sobre algunos aspectos de la cuestión social en el Perú", publicada en enero de 1958, y la organización de la Primera Semana Social de la Iglesia en agosto de 1959. Ambos acontecimientos articularon una visión crítica de los problemas sociales del Perú basada en la doctrina social católica, que planteaba la responsabilidad de los cristianos ante los cambios sociales en marcha.

Para Klaiber, si bien reconoce los esfuerzos previos de obispos como Juan Landázuri en Lima y José Dammert en Cajamarca por implementar las enseñanzas conciliares, la plena recepción del Concilio Vaticano II en el Perú se concretó en 1968. El capítulo IX, "La Iglesia durante el régimen de Velasco, 1968-1975", empieza con una cita del obispo auxiliar de Lima, Luis Bambarén, que ancla esta perspectiva:

Aunque la Iglesia peruana ya venía detectando los problemas de la injusticia social en el país desde tiempo atrás, es entre 1968 y 1970 que adquiere una conciencia crítica de esta realidad y asume globalmente un compromiso con quienes padecen sus consecuencias. (Noticias Aliadas, 18 de octubre de 1972, p. 1, citado por Klaiber, 1996, p. 395)

Este giro se relaciona concretamente con la conferencia de Medellín y el surgimiento de grupos de laicos y sacerdotes que interpretaron la renovación de la Iglesia a la luz del Vaticano II como un llamado a transformar las estructuras sociales injustas en Latinoamérica. Para el Perú, 1968 significó otro hito decisivo: el ascenso al poder de la Fuerza Armada con el golpe de Estado del 3 de octubre del mencionado año. En palabras de Klaiber, en los años de la "primera fase" de la dictadura militar (1968-1975), presidida por el general Juan Velasco Alvarado, "la Iglesia peruana se convirtió en un mo- 
delo para la Iglesia en el resto de América Latina” (p. 395). El autor señaló que "el régimen militar reformista que se instaló en el poder en octubre de 1968 pronto dio un impulso no esperado al proceso de cambios dentro de la Iglesia”, que alentó la implementación del mensaje de Medellín (pp. 404-405).

La tesis tan contundente de Klaiber se sustenta en que la Iglesia peruana fue desafiada a repensar su relación con el Estado y la sociedad por la aceleración de los cambios políticos y económicos durante el régimen militar. Por tanto, ese fue el escenario en que estuvo desafiada a encarnar las enseńanzas del Concilio Vaticano II y, sobre todo, de la Constitución Pastoral Gaudium et spes a través de la interpretación hecha en Medellín. La renovada presencia eclesial entre los sectores populares urbanos y rurales, madurada durante la etapa de modernización, hizo que sacerdotes y laicos fueran testigos de los procesos de politización en los pobladores de las "barriadas" y del campesinado, que en varios sentidos fueron impulsados por el proyecto político de Velasco. De esa manera, el tono reformista del régimen militar "reforzó notablemente las tendencias progresistas en la Iglesia”, pues encontró sintonía entre las reivindicaciones populares, los planteamientos del gobierno y la renovación eclesial impulsada por Vaticano II y Medellín. Incluso "en su afán de legitimar el proceso revolucionario, los militares invitaron a la Iglesia a participar directamente en la formulación y la implementación de muchas de las reformas" (p. 396).

246 En consecuencia, en ese contexto político sui géneris "se aceleró el proceso de concientización social y política que ya había comenzado en Medellín, y de otro, se intensificó el cuestionamiento interno que se había iniciado en el Concilio Vaticano II con el fin de llevar a cabo una profunda renovación de la Iglesia” (pp. 425-426). Los católicos más comprometidos con la reforma conciliar no solo manifestaron más interés en la política y la doctrina social de la Iglesia, sino que 
reconocieron "en el mensaje social de la Iglesia una posibilidad real y positiva para realizar en su tiempo" (p. 427). De esa manera, dieron forma a un modelo de "Iglesia social-política" comprometida con la "concientización" y la "liberación" de los oprimidos, así como con la "lucha popular" (p. 396).

Entre los forjadores de la "Iglesia social-política”, Klaiber sitúa a "grupos de vanguardia" como el movimiento sacerdotal ONIS, la Unión Nacional de Estudiantes Católicos (UNEC) y el movimiento "Fe y Acción Solidaria". Fueron en los encuentros de estas organizaciones donde maduraron las ideas de la teología de la liberación y se articuló una red de actores eclesiales que consideraban que estaban renovando la Iglesia según el espíritu de Vaticano II y Medellín a través de su compromiso con la lucha por un cambio radical de la sociedad peruana. A pesar de reconocer la contribución de esos grupos en acentuar la "impresión pública" del giro progresista de la Iglesia, Klaiber los criticaba (especialmente a ONIS) por cierto elitismo y extremismo ideológico. En sus palabras, al intentar asumir un "papel profético", cayeron en "la pretensión de comprender los grandes problemas socio-políticos mejor que los expertos y de ser los verdaderos intérpretes del sentir de las masas populares, y una actitud de desafío frente a la autoridad" ( $p$. 401). Concretamente, expresaron un fuerte distanciamiento crítico con respecto al régimen militar. Sin embargo, el autor reconoce que, a diferencia de otros movimientos de católicos "radicales" en América Latina, en el Perú se evitaron los enfrentamientos directos con los obispos.

Sin embargo, el hilo conductor del capítulo IX es la actuación del episcopado. Klaiber anclaba la 36. a Asamblea General del Episcopado Peruano, celebrada en enero de 1969, como el evento que definió la recepción del mensaje de Medellín. En esa reunión, se articuló una mirada crítica de la realidad social del Perú que incorporó las conclusiones de la asamblea 
del CELAM y el análisis de la situación política del país bajo el régimen militar. $\mathrm{Al}$ resaltar la permanencia de un "feudalismo colonial" y la responsabilidad de la oligarquía nacional en el subdesarrollo del país, los obispos no solo hacían eco de Medellín, sino que simultáneamente coincidían con los supuestos del proyecto político militar. Según Klaiber, esta afinidad fue promovida por los militares, quienes enfatizaron el carácter humanista, libertario, socialista y cristiano de la "revolución peruana”. Más aún, en sus planteamientos político-ideológicos era clara la influencia del ideario demócrata cristiano.

A pesar de las coincidencias, Klaiber afirma que "la Iglesia nunca legitimó el régimen militar, pero sí aprobó, en líneas generales, las reformas que realizaba" (p. 408). Es decir, se propagó un modelo de "colaboración crítica" y el episcopado respaldó las reformas en un clima de diálogo que no implicó abandonar la prerrogativa de discrepar y plantear alternativas. Incluso, se autorizó la participación de clérigos como funcionarios estatales, siendo los casos más destacados los jesuitas Ricardo Morales Basadre y Romero Luna Victoria, piezas claves de la reforma educativa. Además, a través de su Comisión Episcopal de Acción Social, la Conferencia de Obispos del Perú cumplió la tarea de concientizar sobre el significado de las reformas en curso y brindó aportes reflexivos sobre los principios que debían orientar su realización. Principalmente, el respaldo fue hacia las políticas que promovían una redistribución de la propiedad y la riqueza, como la expropiación de empresas en sectores productivos estratégicos, la reforma agraria, las comunidades industriales y las empresas de propiedad social.

Sin embargo, no faltaron las tensiones, debido a los desencuentros entre el gobierno y las organizaciones populares, cuyas agendas no coincidieron necesariamente. La cercanía de la Iglesia en los medios populares creó un dilema pastoral que, en términos de Klaiber, se resumía en "¿hasta qué punto 
debía colaborar con un gobierno autoritario, por reformista que sea, si esa colaboración traía consigo un distanciamiento del mismo pueblo?” (p. 422). Algunos incidentes de roce son recogidos en el texto de Klaiber, quien apunta que los sacerdotes radicalizados y agentes pastorales de base optaron por respaldar al movimiento popular por encima de la convivencia con el gobierno. Las voces de algunos obispos, como Luis Bambarén y José Dammert, suscribieron esa posición. La expropiación de todos los periódicos principales del país, decretada en julio de 1974, fue un punto de inflexión en la relación entre la Iglesia y el gobierno militar. Lo que constituía un dilema pasó a ser un consenso entre obispos y sectores católicos radicalizados, pues coincidieron en que tal acontecimiento representaba una amenaza de manipulación de la opinión pública y de implantación de un régimen totalitario. Desde entonces, la jerarquía eclesiástica se distanció del gobierno militar.

La destitución del general Velasco de la conducción del gobierno, ocurrida el 29 de agosto de 1975, y su reemplazo por un liderazgo de tendencia derechista implicó "una frustración para muchos grupos eclesiales que esperaron ser testigos de un cambio radical en la sociedad peruana" (p. 427). Sin embargo, para Klaiber, durante los años previos, "la Iglesia en su conjunto cambió de mentalidad substancialmente" al desarrollar una inquietud por la dimensión social y política del trabajo evangelizador. En los años de la "segunda fase" del gobierno militar y el retorno a la democracia en 1980, las transformaciones mencionadas en la Iglesia dieron pie para continuar desarrollando "una acción pastoral más dinámica y actualizada” (p. 427).

Para el autor, dichos ańos marcaron un nuevo periodo de la vida de la Iglesia peruana que transitó hacia un modelo de Iglesia "social-pastoral", en el que el aspecto político fue reinterpretado y desideologizado. Un factor de ese cambio fue 
el fracaso del reformismo "velasquista" que llevó a muchos católicos a "desconfiar de la eficacia de las fórmulas políticas o ideológicas para lograr la transformación de la sociedad" (p. 432). En consecuencia, para el autor, el contexto permitió una crítica al "sobredimensionamiento de lo político en la vida y acción pastoral de algunos cristianos, entre sacerdotes y laicos" en tanto constituía un signo de "inmadurez espiritual" y un reduccionismo de las enseńanzas de Vaticano II y Medellín (p. 432).

Por tanto, esa mirada crítica a los ańos iniciales de la recepción de Vaticano II y Medellín impulsó una resignificación de la "pastoralidad" de la misión de la Iglesia latinoamericana, que profundizó su sentido teológico a la luz del Concilio y del camino recorrido desde $1968^{10}$. La convocatoria de la 3. ${ }^{a}$ conferencia general del CELAM en Puebla (1979) fue el escenario en donde cristalizaron esas discusiones, que dieron forma a un concepto de "pastoral" que enfatizaba la tarea de "procurar el desarrollo armónico del cristiano, sin descuidar ningún aspecto importante de su existencia como ser humano y creyente” (p. 432). En esa línea, Puebla inauguró la búsqueda de una "nueva convivencia eclesial" entre "progresistas" y "conservadores" basada en una "mutua aceptación a base del respeto y del diálogo" (p. 434). Adicionalmente, suscitó un "proceso de maduración" que rectificó los excesos de la "Iglesia social-política", donde en ocasiones se confundió el diálogo responsable y la crítica constructiva por el "disentimiento irresponsable" (p. 433). De esa forma, en el

10 El teólogo jesuita Christoph Theobald (2015) afirma que uno de los legados fundamentales de Vaticano II es el "principio de pastoralidad" como modo de proceder de la Iglesia que toma en cuenta a los destinatarios y la realidad histórica en el proceso de comunicación del depósito de la fe. La reinterpretación de la noción de "pastoral" en el contexto de la conferencia de Puebla puede entenderse siguiendo ese criterio hermenéutico de Theobald. 
modelo de la Iglesia "social-pastoral" de Puebla, los conflictos surgieron no tanto entre "conservadores" y "progresistas", sino entre "sectarios" y "pluralistas", es decir, entre quienes estaban abiertos al diálogo y los que no (p. 434).

Al construir esa interpretación histórica, Klaiber no pierde de vista las tensiones intracatólicas ni los límites de esa "nueva convivencia eclesial" post-Puebla. El periodo abierto en 1968 no solamente fue de renovación y profundización del compromiso con la "cuestión social", sino de división y conflictos. En algunos casos, se trató de recelos debido a la incomprensión entre posiciones extremas, que pudo ser resuelto mediante el espíritu de diálogo y maduración impulsado por la conferencia de Puebla. Por ejemplo, el autor señala que ante las críticas que la tildaron de una excesiva politización, los cristianos asociados a la teología de la liberación empezaron a enfatizar el aspecto espiritual y contemplativo del ser humano durante los años ochenta. Por su parte, la Renovación Carismática, criticada por los "liberacionistas" por sus métodos "alienantes" y norteamericanizados, revaloró la importancia del compromiso social en la vida de cada cristiano (p. 433).

Otra forma de expresión de esos conflictos tuvo que ver con el rechazo del Vaticano II. Al referirse a ese aspecto, Klaiber hace una distinción entre "tradicionalistas" y "conservadores". Los primeros son personas que añoran ciertas tradiciones preconciliares, pero que no están cerradas a los valores fundamentales que resaltó el Vaticano II. Los segundos, entre los cuales ubica al Opus Dei y al Sodalitium Christianae Vitae, insisten no solo en retener formas preconciliares, sino también actitudes como el "verticalismo autoritario", el "unidimensionalismo intelectual", el estilo rígido en la liturgia y la pastoral sacramental, y devociones que refuerzan el individualismo. Además, rechazaron el "cambio social" por su afinidad con posiciones de la derecha política y su interpreta- 
ción del camino abierto por la conferencia de Medellín como "infiltración marxista" en la Iglesia (p. 443). Es a estos grupos a quienes Klaiber califica como "sectarios" y, por tanto, representan amenazas al espíritu de convivencia post-Puebla. Paradójicamente, al descalificar tajantemente a los "grupos conservadores", Klaiber mismo rompe con la "ansiada" tolerancia intraeclesial y proyecta sus propias posiciones sobre los conflictos en marcha.

En cierto sentido, la aproximación de Klaiber a los conflictos entre Medellín y Puebla ofrece una alternativa a la narrativa de la CEHILA, que más bien ve en el proceso abierto en 1968 una gesta heroica por constituir una Iglesia "liberadora" en conflicto con las fuerzas conservadoras que, aliadas con los poderes políticos (sea Estados Unidos, las dictaduras militares o partidos políticos de derecha) buscaban detener ese avance. En ese discurso, Puebla constituyó un triunfo relativo de la opción liberadora que fue combatida en los años sucesivos del pontificado de Juan Pablo II y marginada en la 4. ${ }^{a}$ conferencia del CELAM en Santo Domingo en 1992 (González Faus y otros, 1980; Meléndez, 1995). Para la CEHILA, el proceso que se abrió con Puebla no fue el de la convivencia eclesial, sino el de la resistencia ante el conservadurismo.

Si bien aparece algo de esa lectura en Klaiber, es indiscutible que el autor es capaz de identificar matices y problematizar que la teología de la liberación no es la única forma de recepción del Vaticano II en el Perú y América Latina. Adicionalmente, considera que ciertas expresiones del activismo político católico cayeron en "extremismo", por lo que fue necesaria una actitud de autocrítica y moderación durante la época de Puebla. De hecho, no solamente califica de "sectarios" a los grupos conservadores y su campańa contra la teología de la liberación, sino también a los sacerdotes comprometidos políticamente, como los del Instituto Español de Misiones 
Extranjeras (IEME) en Chimbote o los Equipos de Misión Obrera (EMO) en el Callao, quienes chocaron con sus obispos y rompieron el clima de convivencia post-Puebla (Klaiber, 1996, pp. 449-451).

Esa mirada crítica a la narrativa "liberacionista" guarda relación con el contexto en el que escribe Klaiber. En 1988, cuando se publicó La Iglesia en el Perú, eran conocidas las instrucciones de la Congregación de la Doctrina de la Fe $(1984,1986)$ que fueron el resultado de un proceso de investigación sobre la ortodoxia de la teología de la liberación, realizado durante el pontificado de Juan Pablo II por iniciativa del cardenal Joseph Ratzinger y un sector del CELAM receloso de ese discurso teológico. Dichos documentos, si bien reconocían que la teología de la liberación es una perspectiva auténticamente cristiana, requirieron algunas clarificaciones en torno a la aplicación del método de análisis marxista que ponía en riesgo la comunión eclesial, en particular, la relación entre el pueblo de Dios y la jerarquía de la Iglesia, y legitimaba la violencia como medio de solución de conflictos. Si bien Klaiber expresa su admiración por Gustavo Gutiérrez y el movimiento eclesial asociado a su figura, es claro que el autor asume la interpretación oficial del CELAM, que a partir de las instrucciones vaticanas admitió la legitimidad de la opción preferencial por los pobres y la evangelización liberadora, pero alertando los abusos ideológicos.

Sin embargo, su aproximación a los conflictos intraeclesiales, como el estudio de todo asunto complejo, presenta sus propias limitaciones. En algunos casos, se le puede cuestionar que prioriza una interpretación de los eventos sin cruzarla con otras. Por ejemplo, respecto al incidente en Chimbote de 1981, los sacerdotes del IEME critican que Klaiber solamente tomó en cuenta el testimonio del obispo diocesano. Por tanto, consideran que se excedió al calificarlos de "sectarios" sin tomar en cuenta que ellos estuvieron presentes en otras 
diócesis del país, como Puno, Ica y Lima Sur sin tener ningún conflicto con los respectivos obispos.

Por otro lado, su falta de información le hace caer en simplificaciones. Por citar un ejemplo, es bien escueto al presentar a los grupos conservadores sectarios al punto de caer en imprecisiones. Afirma que Sodalitium tiene una presencia importante en el Seminario de Santo Toribio y pierde de vista que este es un centro de formación de sacerdotes diocesanos. Claramente, confunde Santo Toribio con la Facultad de Teología Pontificia y Civil de Lima, al considerar erradamente que son la misma institución. Quizás, en este caso, opera adicionalmente su falta de simpatía hacia movimientos como el Sodalitium, que se ubicaban en las antípodas de su identidad eclesial. La descripción que hace del movimiento es bastante negativa y, a la vez, más reducida que la que hace del movimiento de la teología de la liberación. Más aún, no logra captar en el texto lo que sí captó la socióloga Milagros Peña (1996) en su estudio sobre los conflictos católicos de los años ochenta. En esa década, Sodalitium logró articular una red eclesial paralela a la de la liberación con su propio discurso teológico, estrategias de evangelización y espacios de socialización, constituyendo una lectura alternativa del Vaticano II.

En este capítulo final, destacan dos rasgos conectados con la manera en que el Concilio Vaticano II y su recepción latinoamericana moldearon el trabajo intelectual de Klaiber. El primero fue la renovación de la actividad misionera de la Iglesia a partir del decreto conciliar Ad Gentes y el distanciamiento con el modelo tradicional de "implantación" de estructuras eclesiásticas y de colaboración ambigua con el colonialismo occidental. Klaiber resaltó la condición del Perú como un país de "misión", que se nutrió del aporte de congregaciones extranjeras ante la escasez de vocaciones sacerdotales y la debilidad de las estructuras eclesiásticas locales. Durante la posguerra, el clero extranjero en el Perú se incrementó nota- 
blemente por la "bonanza de vocaciones" en las Iglesias de los Estados Unidos, Canadá e Irlanda, y la política papal de Pío XII y Juan XXIII de alentar la presencia misionera en América Latina. De acuerdo con Klaiber, entre 1940 y 1969, 42 nuevas órdenes, congregaciones o asociaciones de sacerdotes se instalaron en el Perú. De esa cifra, 25 lo hicieron a partir de 1960 (Klaiber, 1996, p. 376).

En la línea de Vaticano II y Medellín, varias de esas congregaciones fueron autocríticas de ciertas actitudes de "triunfalismo y paternalismo" en su estilo misionero. Por tanto, apostaron por profundizar su contacto con la realidad peruana para distanciarse de la reproducción de esquemas de dominación y dependencia, y fortalecer una evangelización "inculturada" (pp. 388-390). De esa manera, para el autor, luego de 1968 la sensibilidad social y la mística pastoral de un grueso de los misioneros extranjeros se transformó en una conciencia política y una opción por fortalecer la Iglesia local. Varios de ellos participaron en los movimientos eclesiales de "vanguardia" de la Iglesia "social-política" y se hicieron críticos de la política de sus propios países de origen ${ }^{11}$.

En la época de la Iglesia "social-pastoral", la "nueva convivencia eclesial" permitió una profundización del trabajo misionero. Al respecto, Klaiber destaca el trabajo eclesial en los "pueblos jóvenes", el sur andino y la Amazonía, denominándolas como "áreas pastorales especiales" que por compartir rasgos similares llevan a cabo "una acción pastoral de conjunto notablemente dinámica e innovadora” (p. 455). Es interesante que las zonas consideradas como más activas pas-

$11 \mathrm{Al}$ respecto, es interesante el dato proporcionado por Klaiber sobre el respaldo de un grupo de 136 sacerdotes de los Estados Unidos a la expropiación de la empresa norteamericana International Petroleum Company, una de las primeras acciones político-simbólicas del gobierno militar (1996, p. 410). 
toralmente son justamente aquellas a cargo principalmente de los misioneros extranjeros. Lo antes dicho nos lleva a afirmar que, para Klaiber, una de las claves de su lectura histórica fue la renovación de la "misión" a la luz de Vaticano II y su recepción latinoamericana, lo que guarda relación con su pertenencia a la Compañía de Jesús, una orden religiosa con carisma misionero.

El segundo rasgo es que la narrativa histórica de Klaiber está influenciada por la eclesiología conciliar que comprende a la Iglesia como el pueblo de Dios, donde todos los bautizados son miembros plenos de la misión evangelizadora. Por tanto, la dimensión jerárquica y clerical queda relativizada ante la primacía del cuerpo diverso formado por los creyentes. Durante el posconcilio, una de las consecuencias de ese modo de acercarse a la Iglesia ha sido la promoción del rol de los laicos en la vida y la misión eclesiales.

$\mathrm{Al}$ respecto, en su libro, Klaiber hace eco de la eclesiología conciliar al incorporar la acción del laicado. En la etapa modernizadora, menciona a la Acción Católica Peruana, al Partido Demócrata Cristiano, al Movimiento Familiar Cristiano y a los Cursillos de Cristiandad. Por su parte, reconoce el protagonismo de la UNEC y el movimiento Fe y Acción Solidaria en la formación de la Iglesia "social-política" y en la propagación de la teología de la liberación. No obstante, en la época de la Iglesia "social-pastoral" explica la diversidad de cuerpos laicales presentes en la Iglesia peruana y resalta a las comunidades eclesiales de base, la Renovación Carismática, el Movimiento Neocatecumenal y los grupos conservadores "sectarios".

Aun cuando es la eclesiología del "pueblo de Dios" la que moldea los intereses intelectuales de Klaiber, en la práctica, su libro reproduce el esquema tradicional de la historiografía católica, en la que los obispos, los clérigos y las órdenes religiosas son 
los grandes protagonistas de la historia de la Iglesia. Esta limitación puede atribuirse al hecho de que para Klaiber uno de los legados más importantes del modelo "social-pastoral" fue "el esfuerzo de formar un laicado cada vez más consciente de su rol en la Iglesia" (p. 506), pero eso era un proceso incipiente y en proceso en los tiempos en los que él escribió. De hecho, el aterrizaje de la eclesiología del pueblo de Dios en una mentalidad, estilos de vida y estructuras pastorales es aún una tarea pendiente en toda la Iglesia global.

\section{A modo de conclusión: Jeffrey Klaiber S. J. y la recepción in- acabada del Concilio Vaticano II en el Perú}

Jeffrey Klaiber pone fin a su obra con la visita pastoral de Juan $\mathrm{Pa}$ blo II al Perú en febrero de 1985. Desde su perspectiva, la algarabía con que el papa polaco fue recibido da cuenta de que la religión ocupaba un papel primordial en la formación de una identidad común y una conciencia cívica entre los peruanos. En ese sentido, el autor afirma que "la Iglesia ha hecho un aporte substancial a la formación del Perú como sociedad y nación”, en tanto su labor evangelizadora realizada desde el siglo XVI "difundió los primeros símbolos comunes que unían a todas las culturas y todos los grupos sociales en el Perú" (Klaiber, 1996, p. 508).

A pesar de esta valoración positiva inicial, su balance histórico no es para nada apologético. Klaiber señala que la Iglesia no solo ha influido en la sociedad peruana, sino que también ha sido moldeada por el mundo social y cultural en el que ha desarrollado su misión, compartiendo con frecuencia "los mismos defectos". Por ello, parafraseando al intelectual aprista Luis Alberto Sánchez, afirma que la Iglesia peruana es una "Iglesia adolescente", que desde la Independencia se ha visto obligada a "descubrir una nueva identidad", que implicaba ganar autonomía ante el Estado (pp. 508-509).

Siguiendo el razonamiento de Klaiber, hacia fines de los 
ochenta, dos eran los retos de la Iglesia peruana para alcanzar su "adultez", los cuales, adicionalmente, fueron los ejes articuladores del argumento de su obra. El primero apunta a la formación de "cristianos comprometidos", es decir, con un sentido de pertenencia a la vida de la Iglesia, un espíritu de militancia y una formación intelectual apropiada para incidir positivamente en la sociedad peruana. Si bien reconoce que este tema ha sido central en la trayectoria del catolicismo peruano en la época republicana, repara en que solo ciertos grupos minoritarios participaban de ese espíritu. Más bien, primaba una "religiosidad popular" que, aunque representa una riqueza cultural y espiritual, acontece "al margen de la Iglesia", siendo "una fuerza potencial que se podría traducir en algo más 'substancial': un compromiso más profundo con la Iglesia o con la acción de construir una sociedad más justa” (p. 510). Esta debilidad del "sentido eclesial" entre los fieles profundizó la ineficacia pastoral y la frágil institucionalidad de la Iglesia peruana, cuyo signo claro era la escasez de sacerdotes locales y la dependencia del clero y laicos extranjeros.

Segundo, la apertura de la Iglesia a la sociedad peruana es un elemento que orientaba la interpretación histórica de Klaiber. Por eso, el autor subraya la colaboración con la construcción de una sociedad justa, especialmente en el servicio a los sectores más excluidos del Perú, y el respeto del pluralismo externo, pero también interno de la Iglesia. Para el historiador jesuita, en esa actitud de apertura, diálogo y responsabilidad social radicó uno de los cambios más significativos de la renovación del catolicismo peruano luego del Vaticano II y su recepción en Medellín y Puebla. En ese sentido, Klaiber expresaba su preocupación ante los grupos de "mentalidad sectaria" que no solamente no estaban preparados para navegar por una época de pluralismo, sino que combatían abiertamente este nuevo modo de ser Iglesia. A eso se sumaba la falta de nivel intelectual en el clero y las congregaciones religiosas, y la ausencia de pensadores cristianos en las universidades públicas

Revista del Instituto Riva-Agüero 
y en las privadas no confesionales. Por lo tanto, "la capacidad de la Iglesia para entrar en un diálogo creativo con la cultura y la ciencia es muy limitada” (p. 511). Esta última afirmación sigue siendo, desafortunadamente, cierta.

El balance conclusivo de Klaiber redondea su principal interrogante académica: jen qué medida la Iglesia peruana ha sido capaz de transformarse en una institución moderna y, a la vez, de entrar en diálogo con la cultura moderna del mundo contemporáneo y la complejidad del tejido social peruano? Estas preguntas, sin duda, son eco de una de las dimensiones estructuradoras de las motivaciones, los textos y el espíritu del Concilio Vaticano II. Si bien Klaiber no define qué entiende por "moderno", de su obra se desprende que se trata de la capacidad de la Iglesia de planificar el trabajo pastoral, articular una reflexión teológica en diálogo con las ciencias contemporáneas y el compromiso socio-político con los cambios en el Perú. Como señalamos, para Klaiber, la constitución Gaudium et spes era el documento clave para entender la recepción del concilio en América Latina y el Perú. Y esa afirmación no solamente era una categoría que aplicaba al análisis de los hechos y procesos. Eran los anteojos con los cuales comprendía su pertenencia al cuerpo eclesial y que, por tanto, moldearon su aproximación intelectual. Por ello, es interesante que el cierre de su libro sea una constatación de las limitaciones de la Iglesia peruana en la consecución de la renovación pastoral y un llamado a entender la recepción de Vaticano II como un proceso inacabado. La modernización eclesial o, en el lenguaje conciliar, su "puesta al día" (aggiornamento), era una tarea pendiente.

Siendo el Vaticano II tan importante en la obra de Klaiber, parece oportuno recalcar este aspecto. Su marco de análisis sobre la historia del catolicismo está influenciado por dos categorías de la eclesiología conciliar. La primera es que la Iglesia siempre se desenvuelve en el mundo, no frente o fuera del 
mundo, como lo resaltó Gaudium et spes. La segunda, como lo indica Lumen gentium, es que dicha Iglesia está constituida primero como un grupo social, "el pueblo de Dios" que se desenvuelve en un espacio y tiempo concretos. Ambos elementos son claves para entender la valoración de la sociedad y su relación bidireccional con la Iglesia, antes incluso que la perspectiva historiográfica clásica centrada en el conflicto político entre el Estado y la Iglesia, o solo en las biografías de personajes eclesiásticos.

Por tanto, Klaiber entiende a la Iglesia como una comunidad histórica que se desenvuelve en el devenir del país, asumiendo sus pasivos, sus dilemas y sus herencias. El peso del contexto es central para entender las reacciones y la toma de posiciones de la Iglesia en el escenario peruano. Su actitud de resistencia e intransigencia ante una sociedad en cambio revela las tensiones internas de la misma Iglesia, que no solo es comunidad, sino una institución socio-política en el país. En este punto, Klaiber recoge matizadamente la diferencia entre la Iglesia "oficial" y la Iglesia "popular" desarrollada por la teología y la historiografía católica de corte liberacionista. Esta entrada le permite a Klaiber distinguir entre la intransigencia y el "conservadurismo" institucional, y las muestras de religiosidad popular más vinculadas a los sectores populares del país, ajenas a los conflictos ideológicos de sus pastores y sus pares laicos de clase media y alta. La vida social de estas dos comunidades creyentes, una expresada en la oficialidad institucional y la otra en la praxis piadosa, corre paralelamente en la narrativa historiográfica de Klaiber. Aunque es oportuno decir que buena parte de su investigación estudia a la denominada Iglesia "oficial" y los cambios que la acercaron a los sectores populares.

En esta trayectoria de un mayor involucramiento de la Iglesia en la realidad del país y sus resistencias, es sugerente la omisión de los procesos socio-políticos de los años ochenta. La crisis económica, la violencia política y las violaciones a los 
derechos humanos no aparecen como terrenos donde la Iglesia se hace presente. Sin embargo, ese silencio es atribuible no a una falta de interés por parte de Klaiber, sino a fenómenos que recién se estaban conociendo y reflexionando. De hecho, a mediados de los ochenta, Klaiber (1987b) fue coordinador de un proyecto de investigación sobre los orígenes culturales de la violencia en el Perú, que reunió a un equipo interdisciplinario para pensar un tema tan necesario en la discusión nacional.

En ese sentido, su libro Iglesia, dictaduras y democracia en América Latina (1997), publicado una década después de La Iglesia en el Perú, contiene un estudio pionero sobre el rol de la Iglesia católica peruana durante la época de la violencia. $\mathrm{Su}$ hipótesis es que en aquellas regiones donde el estilo pastoral se transformó según el espíritu de Vaticano II y las conferencias de Medellín y Puebla, Sendero Luminoso encontró más dificultades para actuar, pues se encontró con un tejido social sólido y dirigentes que, en líneas generales, había sido promovido por los agentes pastorales católicos. La Iglesia, por ende, era descrita como un actor comprometido con el fortalecimiento de la sociedad civil, la denuncia de violaciones de derechos humanos y la asistencia humanitaria, y con la promoción de la cohesión social y la resistencia ciudadana pacífica entre las comunidades afectadas por la violencia. Más adelante, Klaiber asesoró a la Comisión de la Verdad y Reconciliación (CVR, 2003) en la elaboración del capítulo referido a las comunidades de fe, lo que le dio un valor público a su trabajo intelectual.

Sin negar lo anterior, en La Iglesia en el Perú, Klaiber responde a otra problemática de los años ochenta, en la que su interpretación es más nítida: los límites de la convivencia intraeclesial post-Puebla y los cuestionamientos a la ortodoxia de la teología de la liberación. Es sintomático que en torno a la publicación de esta obra hayan aparecido otros trabajos 
sobre los cambios sociales de la Iglesia en el posconcilio. El abogado Luis Pásara (1986), en un texto que generó polémica, habló del "estilo católico radical" que facilitó la migración de numerosos católicos hacia la militancia en partidos de izquierda. Por su parte, investigadores del Instituto Bartolomé de las Casas, fundado por el teólogo Gustavo Gutiérrez, publicaron una serie de ensayos en los que discutieron la idea de una "radicalización católica" (Romero, 1987; Romero y Tovar, 1987). En ellos, recalcaron las transformaciones de las relaciones de la Iglesia católica con el Estado y la sociedad durante el periodo del posconcilio en una línea afín a la CEHILA y sin abordar en profundidad los conflictos intraeclesiales.

Aun cuando la posición de Klaiber fue la de promover una cultura de pluralismo y el diálogo desde la perspectiva de Puebla, su libro recibió varios cuestionamientos de las dos posiciones predominantes en los conflictos intracatólicos de los años ochenta. Por un lado, el historiador Fernando Iwasaki criticó a Klaiber porque su interpretación estaba dominada por el estudio del trabajo pastoral con los sectores populares, lo que traslucía su identificación con la teología de la liberación. Los sesgos de Klaiber, según Iwasaki (1988), lo llevaban a reproducir la opinión de los "voceros oficiosos del marxismo criollo" que etiquetaban al Opus Dei y el Sodalitium como grupos conservadores opuestos al Concilio Vaticano II, desconociendo que estos movimientos eclesiales participaban del espíritu conciliar y del trabajo de promoción social entre los sectores populares. Por su parte, los intelectuales afines a la corriente "liberacionista" fueron recelosos del libro de Klaiber por su crítica al radicalismo de ciertos agentes pastorales que sobredimensionaron el rol político de la Iglesia. Considerando que se trataba de un argumento que legitimaba los cuestionamientos a la ortodoxia de la teología de la liberación, tomaron el libro con pinzas. 
En el fondo, la recepción inicial del libro de Jeffrey Klaiber reveló que el "consenso eclesial entre conservadores y progresistas" por el que abogaba en su texto no se había logrado plenamente en la Iglesia peruana post-Puebla. Las críticas de un lado y del otro apuntaban a que no había un terreno propenso para acoger una interpretación favorable al consenso, pues este no existía en la práctica. La Iglesia en el Perú, al publicarse en el contexto de la polémica sobre la teología de la liberación, impidió a los actores del momento tomar distancia de sus propias posiciones y recoger el constructo complejo y crítico planteado por Klaiber. La manera predominante de leer el libro estuvo dominada por el criterio de cuánto aportaba a legitimar una de las dos posiciones en debate. Sin duda, como resalta Fernando Armas (2002), la monografía analizada hace un uso del pasado para afianzar el presente y el futuro de la Iglesia peruana, por lo que construye imágenes para reforzar la identidad de una Iglesia comprometida frente a una Iglesia conservadora. Sin embargo, el texto de Klaiber tiene varios matices críticos que los interlocutores del momento no captaron, quizás por el contexto histórico en el cual lo leyeron.

Yendo más allá de los años convulsionados en que vio la luz La Iglesia en el Perú, esta es una obra de referencia obligatoria para el estudio del catolicismo peruano. Plantea hipótesis audaces que requieren ser problematizadas a través de estudios de caso y miradas más focalizadas. Quienes escribimos este artículo hemos partido de los planteamientos de Klaiber para ofrecer mayores luces sobre procesos específicos de la historia de la Iglesia en el Perú. Rolando Iberico (2017a; 2017b) ha estudiado el ascenso del ultramontanismo en la Iglesia peruana a partir de los debates teológico-políticos en la coyuntura entre 1855 y 1860, así como la formación de las primeras asociaciones laicales en Arequipa, previas a la Acción Católica de 1935. Por su parte, Juan Miguel Espinoza (2015) reconstruyó la experiencia del curso de teología 
organizado por Gustavo Gutiérrez y otros intelectuales como espacio de articulación de la red eclesial asociada a la teología de la liberación.

En la línea de lo dicho, quienes escribimos este texto, estamos en deuda con el padre Jeffrey Klaiber por razones que van más allá de ser la "bibliografía obligatoria”. Él fue profesor nuestro en el pregrado de Historia en la PUCP y un interlocutor riguroso y generoso. Como intelectual y presbítero supo acoger y promover nuestras inquietudes académicas por la historia de la Iglesia y, con su propio testimonio, nos animó a convertirlas no solo en un mero saber, sino en una vocación y un servicio al pueblo de Dios. Por ello, esta contribución, apelando a palabras de Ignacio de Loyola, es una manera de corresponder a "tanto bien recibido" de nuestro maestro.

Nos parece que el mejor homenaje radica en seguir retomando las intuiciones de su obra, investigándolas con el rigor propio del método histórico, el compromiso ético y, en la medida de lo posible, con la distancia crítica que exige nuestra pertenencia a la Iglesia. Nos toca seguir su ejemplo de leer críticamente la praxis de la Iglesia a partir de su lugar en el mundo y cómo esto plantea redefinir el anuncio del Evangelio y la promesa utópica del Reino de Dios con una nueva humanidad más justa y fraterna. Sin lugar a dudas, en La Iglesia en el Perú hay vacíos y aspectos discutibles, pero es innegable que sin ese libro no es posible seguir planteando nuevas preguntas sobre la historia del catolicismo peruano.

Recibido: 18 de febrero de 2020

Aprobado: 17 de mayo de 2020 


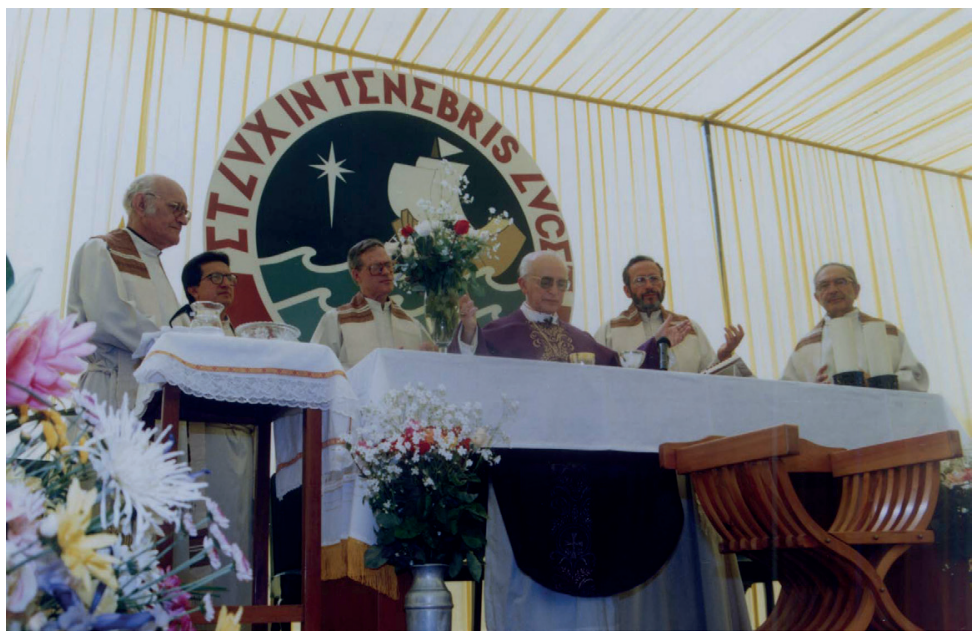

Jeffrey Klaiber S.J. concelebra la Eucaristía de Bienvenida al Cachimbo. De izquierda a derecha: Luis Martínez S.J., director del CAPU; Heliodoro Gijón MSPS; Jeffrey Klaiber S.J.; cardenal Augusto Vargas Alzamora, S.J. arzobispo de Lima; Alberto Simons S.J.; y Luis Fernando Crespo. Fuente: Archivo de la Universidad. 


\section{Referencias bibliográficas}

ARMAS, F.

Un discurso sobre el pasado: Las Casas, el lascasianismo y la utopía de la teología de la liberación. En A. de Zaballa (Comp.), Utopía, mesianismo y milenarismo. Experiencias latinoamericanas (pp. 93-112). Lima: Universidad San Martín de Porres.

BOFF, L.

(1984) Significado teológico de 'Pueblo de Dios' e 'Iglesia popular’. Concilium (196), 441-454.

\section{CONSEJO EPISCOPAL LATINOAMERICANO}

(2018) [1968] Segunda Conferencia General del Episcopado Latinoamericano: 50 años Medellín. Bogotá: Pontificia Universidad Javeriana.

CHESNUT, G.

(1986) The First Christian Histories: Eusebius, Socrates, Sozomen, Theodoret, and Evagrius. Macon, GA: Mercer University Press.

\section{COMISIÓN DE LA VERDAD Y RECONCILIACIÓN}

(2003) La Iglesia católica y las iglesias evangélicas. En Informe final (t, III, pp. 385-490). Lima: Comisión de la Verdad y Reconciliación.

\section{COMISIÓN TEOLÓGICA INTERNACIONAL}

(2018) La sinodalidad en la vida y la misión de la Iglesia. Roma:

Librería Editrice Vaticana. Recuperado de http:// www.vatican.va/roman_curia/congregations/cfaith/ cti_documents/rc_cti_20180302_sinodalita_sp.html

CONCILIO VATICANO II

(1964) Lumen gentium: Constitución dogmática sobre la Iglesia. Recuperado de http://www.vatican.va/archive/ hist_councils/ii_vatican_council/documents/vatii_const_19641121_lumen-gentium_sp.html 
CONCILIO VATICANO II

(1965) Decreto Ad Gentes sobre la actividad misionera de la Iglesia. Recuperado de http://www.vatican.va/archive/hist_councils/ii_vatican_council/documents/ vat-ii_decree_19651207_ad-gentes_sp.html

CONCILIO VATICANO II

(1965) Gaudium et spes: Constitución pastoral sobre la Iglesia en el mundo contemporáneo. Recuperado de http:// www.vatican.va/archive/hist_councils/ii_vatican_ council/documents/vat-ii_const_19651207_gaudium-et-spes_sp.html

CONGREGACIÓN PARA LA DOCTRINA DE LA FE

(1984)

Instrucción sobre algunos aspectos de la teología de la liberación. Recuperado dehttp://www.vatican.va/ roman_curia/congregations/cfaith/documents/ rc_con_cfaith_doc_19840806_theology-liberation_ sp.html

CONGREGACIÓN PARA LA DOCTRINA DE LA FE

(1986) Instrucción Libertatis Conscientia sobre libertad cristiana y liberación. Recuperado de http://www.vatican. $\mathrm{va/roman \_ curia/congregations/cfaith/documents/}$ rc_con_cfaith_doc_19860322_freedom-liberation_ sp.html

DI STEFANO, R.

(2015) Las trampas sutiles del ultramontanismo. Debate de Redhisel. Recuperado de https://www.teseopress. $\mathrm{com} /$ debatesredhisel2/chapter/55/

DRAKE, H.A.

(1976) In Praise of Constantine: A Historical Study and New Translation of Eusebius' Tricennial Orations. Berkeley: University of California Press. 
DUSSEL, E.

(1979) De Medellin a Puebla. Una década de sangre y esperanza (1968-1979). México: Centro de Estudios Ecuménicos, A.C. https://doi.org/10.11606/issn.23169141.v0i115p61-87

DUSSEL, E.

(1983) Historia general de la Iglesia en América Latina. Tomo I-1: Introducción general a la historia de la Iglesia en América Latina. Salamanca: CEHILA, Ediciones Sígueme.

ESPINOZA, J. M.

(2015) Las 'Jornadas de Reflexión Teológica' y el desarrollo de un proyecto eclesial posconciliar asociado a la teología de la liberación en el Perú: discurso teológico, redes sociales y cultura eclesial (1969-2000) (Tesis para optar por el grado de magíster en historia). Pontificia Universidad Católica del Perú, Escuela de Posgrado, Lima.

FAGGIOLI, $M$.

(2012)

Vatican II. The Battle for Meaning. Mahwah: Paulist Press.

GALLI, C. M.

(2016) La reforma misionera de la Iglesia según el papa Francisco: La eclesiología del Pueblo de Dios evangelizador. En A. Spadaro, C.M. Galli (Eds.), La reforma y las reformas (pp. 51-77). Cantabria: Sal Terrae.

GIBELLINI, R.

268 (1998) La teología del siglo XX (2. ${ }^{\text {a }}$ ed.). Santander: Sal Terrae.

GONZÁLEZ FAUS, J. I.

(1980) La batalla de Puebla. Barcelona: Laia.

GRANFIELD, P.

(1979) The Church as Societas Perfecta in the Schemata of Vatican I. Church History 48 (4), 431-446. https:// doi.org/10.2307/3164535 
HÜNERMANN, P.

(2014) El texto pasado por alto. Sobre la hermenéutica del Concilio Vaticano II. En El Vaticano II como software de la Iglesia actual (pp. 145-173). Santiago de Chile: Centro Teológico Manuel Larraín.

IBERICO, R.

(2015) La fe de todos los siglos: una aproximación a la relación entre teología ultramontana e historiografía católica en el Perú. Religión y Cultura, 9 (1), 9-33.

IBERICO, R.

(2017a) La república católica dividida: ultramontanos y liberales-regalistas (Lima, 1855-1860). Lima: Instituto Riva-Agüero y Fundación Manuel J. Bustamante de la Fuente.

IBERICO, R.

(2017b) La Roma del Perú: resurgimiento católico, espacio público y politica en Arequipa (1860-1925) (Tesis para optar el grado de magíster en historia). Pontificia Universidad Católica del Perú, Escuela de Posgrado, Lima.

IVEREIGH, A.

(2019) Wounded Shepherd: Pope Francis and His Struggle to Convert the Catholic Church. New York: Henry Holt and Company.

IWASAKI, F.

Reseña de Klaiber, Jeffrey. La Iglesia en el Perú: Su historia social desde la Independencia. Histórica, 12 (2), 214-216.

KLAIBER, J.

(1986) The Battle over Private Education in Peru, 19681980: An Aspect of the Internal Struggle in the Catholic Church. The Americas, 43 (2), 137-158. 
KLAIBER, J. (Coord.)

(1987a) Historia general de la Iglesia en América Latina: Perú, Bolivia y Ecuador (v. VIII). Salamanca: CEHILA, Ediciones Sígueme.

KLAIBER, J. (Ed.).

(1987b) Violencia y crisis de valores en el Perú. Lima: Pontificia Universidad Católica del Perú.

KLAIBER, J.

La Iglesia en el Perú: su historia social desde la Independencia (2. ${ }^{a}$ ed.). Lima: Pontificia Universidad Católica del Perú.

KLAIBER, J.

(1996) La Iglesia en el Perú: su historia social desde la Independencia (3. ${ }^{a}$ ed.). Lima: Pontificia Universidad Católica del Perú.

KLAIBER, J.

(1997) Iglesia, dictaduras y democracia en América Latina. Lima: Pontificia Universidad Católica del Perú.

LUCIANI, R.

(2016) El Papa Francisco y la teología del pueblo. Madrid: PPC. https://doi.org/10.1093/ oso/9780190851408.001.0001

MASSA, M.

The Structure of Theological Revolutions. How the Fight over Birth Control Transformed American Catholicism. New York: Oxford University Press.

MELÉNDEZ, G.

(1995) El concilio plenario y las conferencias generales del episcopado de América Latina y el Caribe. En E. Dussel, Resistencia y esperanza: historia del pueblo cristiano en América Latina y el Caribe (pp. 599-623). San José: Departamento Ecuménico de Investigaciones. 
MENÉNDEZ MARTÍNEZ, V.

(2002). La misión de la Iglesia. Un estudio sobre el debate teológico y eclesial en América Latina (1992-1995) con atención al aporte de algunos teólogos de la Compañía de Jesús. Roma: Editrice Pontificia Università Gregoriana.

MENOZZI, D.

(1987). El anticoncilio (1966-1984). En G. Alberigo y J. P. Jossua (Eds.), La recepción del Vaticano II (pp. 385413). Madrid: Cristiandad.

O’MALLEY, J.

(1982, 9 de octubre). Church History in Service of the Church. America, 188-190.

O’MALLEY, J.

(2010). What Happened at Vatican II. Cambridge: The Belknap Press of Harvard University Press. https://doi. org/10.2307/j.ctvjf9v70

PARRA, F.

(2009)

Teología del cuerpo místico, comunión de los santos y pensamiento social en San Alberto Hurtado. La influencia de Émile Mersch y Karl Adam. Teologia y Vida, L (4), 797-835. https://doi.org/10.4067/ S0049-34492009000300005

PÁSARA, L.

Radicalización y conflicto en la Iglesia peruana. Lima: Ediciones El Virrey.

PEÑA, M.

(1995) Theologies and Liberation in Peru. The Role of Ideas in Social Movements. Philadelphia: Temple University Press.

PÍO XII

(1943). Carta encíclica Mystici corporis Christi. Recuperado de http://www.vatican.va/content/pius-xii/es/en- 
cyclicals/documents/hf_p-xii_enc_29061943_mystici-corporis-christi.html

RICHARD, P.

(1980) La Iglesia latinoamericana entre el temor y la esperanza. Costa Rica: Departamento Ecuménico de Investigaciones.

ROMERO, C.

Iglesia en el Perú: compromiso y renovación (19581984). Lima: Instituto Bartolomé de las Casas.

ROMERO, C., TOVAR, T.

(1987) Cambios en la Iglesia peruana. En J. Klaiber (Coord.). Historia general de la Iglesia en América Latina: Perú, Bolivia y Ecuador (v. VIII, pp. 418-446). Salamanca: CEHILA, Ediciones Sígueme.

THEOBALD, C.

(2015) The Principle of Pastorality at Vatican II: Challenges of a Prospective Interpretation of the Council. In M. Faggioli and A. Vicini (Eds.), The Legacy of Vatican II (pp. 26-37). Mahwah, NJ: Paulist Press.

VARGAS UGARTE, R.

(1962) Historia de la Iglesia en el Perú, 1800-1900 (vol. 5). Burgos: Imprenta Santa María.

WOOD, S. Ecclesiology. Ecclesiology, 7 (2), 147-172. https://doi. org/10.1163/174553111X559517 